\title{
The Effect of Nb Supplement on Material Characteristics of Iron with Lamellar Graphite
}

\author{
Ahmet Oktay Devecili and Rifat Yakut \\ Hema Endüstri A.S. Organized Industrial Zone, Çerkezköy, 59501 Tekirdăg, Turkey \\ Correspondence should be addressed to Rifat Yakut; rifatyakut@hattat.com.tr
}

Received 2 May 2013; Accepted 3 December 2013; Published 22 January 2014

Academic Editor: Steve Bull

Copyright (C) 2014 A. O. Devecili and R. Yakut. This is an open access article distributed under the Creative Commons Attribution License, which permits unrestricted use, distribution, and reproduction in any medium, provided the original work is properly cited.

In this experiment a cast iron alloy consisting of $0.019,0.151,0.431$, and $0.646 \%$ niobium by weight was set and the microstructure solidification of iron with lamellar graphite was provided. These alloys were subjected to an abrasion test and chemical analyses of the microstructure were done by using scanning electron microscopy (SEM) and energy dispersive X-ray spectrometry (EDS). In addition to this, phase compositions were characterised by X-ray diffraction (XRD). Tests of mechanical strength, hardness, and tension were also applied to the alloys. The results of this experiment demonstrated that the addition of niobium to iron with lamellar graphite caused an increase in the abrasion resistance by $15 \%$. This experiment shows that adding niobium improves the mechanical properties of grey cast iron.

\section{Introduction}

More than $90 \%$ of the cast iron in industry consists of iron with lamellar graphite. High compression strength, high thermal conductivity, ability to isolate vibration, better machinability than other cast irons, good mould filling ability, and relatively low costs (lower than $20-40 \%$ of the cost of steel) are the main reasons for the extensive usage of iron with lamellar graphite in industries such as the automotive industry. Iron with lamellar graphite can be used as clutch covers and pressure plates in the automotive industry because of its good friction properties, as well as for engine blocks, brake discs, flywheels, cylinder sleeves, and piston rings [1-6]. Lamellar graphite cast iron shows great strength and abrasion resistance when used as a cylinder sleeve [7]. To improve the abrasion resistance of cast iron, some early works describe various aspects of small additions of niobium $(<0.5 \%)$ [8-12]. These works have found minor changes to the austenite stability, refining of graphite structure, very small precipitations of $\mathrm{Nb}(\mathrm{C}, \mathrm{N})$, and so on. Some of these investigations were misinterpreted or misunderstood, possibly due to the lack of advanced measuring techniques such as high-resolution microscopy as well as an incomplete understanding of the basic thermodynamics. Therefore, in this study, the effect of the addition of niobium on the mechanical strength and abrasion resistance of grey cast iron was investigated.

\section{Experimental Study and Preparation of Samples}

Table 1 shows the chemical analysis of alloys A, B, C, and $\mathrm{D}$, which were cast separately at $1450^{\circ} \mathrm{C}$ into sand moulds $150 \mathrm{~mm}$ high and $30 \mathrm{~mm}$ in diameter after being melted in a medium-frequency induction melting furnace. During casting, $0.1 \%$ strontium-based inoculation material was added to the cast. The chemical composition of the inoculation material is shown in Table 2.

The samples were removed from the sand moulds at room temperature. Disc-shaped samples, $5 \mathrm{~mm}$ thick, were extracted and removed from the cylindrical samples using a water-cooled silicon carbide ( $\mathrm{SiC}$ ) saw (Figure 1). The surfaces of the samples were prepared by 600 grid SIC sandpaper for chemical analysis and then washed with alcohol and dried. The chemical analyses were done by SpectroMax LMF14 device in cast iron analysis mode. For the metallographic examination, samples were prepared using $180,320,600,800$, and 1000 grid $\mathrm{SiC}$ sand papers and polished 
TABLE 1: Chemical composition of samples.

\begin{tabular}{|c|c|c|c|c|c|c|c|c|c|c|c|c|c|c|c|c|}
\hline \multicolumn{17}{|c|}{ Chemical composition of samples (\%wt) } \\
\hline Sample no. & $\mathrm{C}$ & $\mathrm{Si}$ & $\mathrm{Mn}$ & $\mathrm{P}$ & S & $\mathrm{Mg}$ & $\mathrm{Cr}$ & $\mathrm{Ni}$ & Mo & $\mathrm{Cu}$ & $\mathrm{Al}$ & $\mathrm{Ti}$ & $\mathrm{Nb}$ & $\mathrm{Sb}$ & $\mathrm{Bi}$ & $\mathrm{V}$ \\
\hline A & 3.664 & 1.855 & 0.574 & 0.014 & 0.088 & 0.001 & 0.201 & 0.003 & 0.004 & 0.496 & 0.006 & 0.007 & 0.646 & 0.015 & 0.001 & 0.004 \\
\hline B & 3.684 & 1.861 & 0.578 & 0.017 & 0.091 & 0.002 & 0.211 & 0.003 & 0.004 & 0.512 & 0.007 & 0.008 & 0.431 & 0.017 & 0.001 & 0.004 \\
\hline $\mathrm{C}$ & 3.618 & 1.95 & 0.521 & 0.013 & 0.088 & 0.002 & 0.191 & 0.003 & 0.004 & 0.523 & 0.006 & 0.006 & 0.151 & 0.015 & 0.003 & 0.003 \\
\hline $\mathrm{D}$ & 3.652 & 1.883 & 0.544 & 0.011 & 0.092 & 0.002 & 0.201 & 0.004 & 0.003 & 0.551 & 0.007 & 0.005 & 0.019 & 0.016 & 0.001 & 0.004 \\
\hline
\end{tabular}

TABLE 2: Chemical composition of the inoculation material.

\begin{tabular}{lcccccccc}
\hline Inoculation material & $\% \mathrm{Si}$ & $\% \mathrm{Ca}$ & $\% \mathrm{Ba}$ & $\% \mathrm{Sr}$ & $\% \mathrm{Zr}$ & $\% \mathrm{Ce}$ & $\% \mathrm{Mn}$ & $\% \mathrm{Al}$ \\
\hline $\mathrm{Sr}-50$ & $46-50$ & $0.1 \mathrm{max}$ & - & $0.6-1.0$ & - & - & - & $0.5 \mathrm{max}$. \\
\hline
\end{tabular}

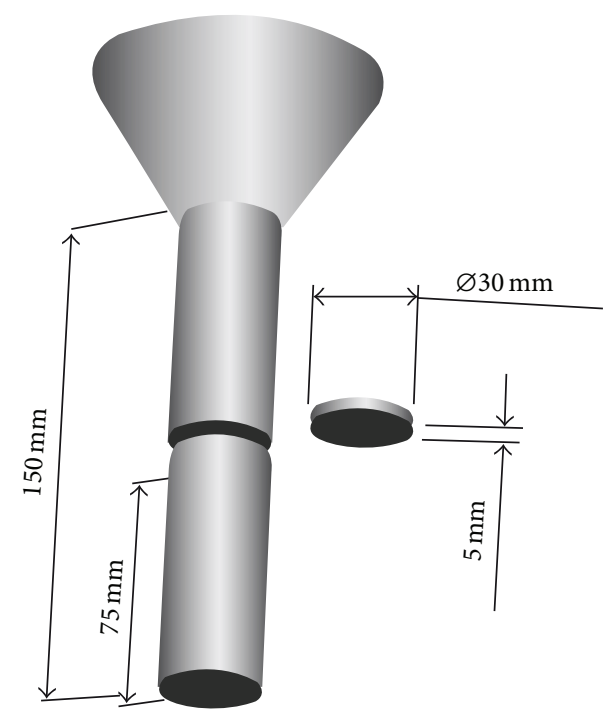

FIGURE 1: Schematic of the parts where samples were removed.

in a polishing device with $3 \mu \mathrm{m}$-particle-sized diamond paste solution. Polished sample surfaces were washed with $98 \%$ pure ethyl alcohol and then dried.

\section{Results and Discussion}

3.1. SEM and EDS Analyses. Sample surfaces were examined in back-scatter electron (BSE) mode using a Philips XL30/SFE SEM device. An EDS analysis was performed on areas flagged by the EDS analyser on the SEM device.

Figure 2 shows the microstructure of sample A. It has a cast iron lamellar graphite microstructure and type A graphite morphology. The zones are indicated by circles in the related picture in sample A. The zones are analysed by EDS and it is confirmed that these zones have high amounts of $\mathrm{Nb}$ elements. Figure 3 shows the microstructure picture of sample B, taken by SEM. The related picture sample B shows the EDS analysis of the areas in red and it is confirmed that these areas contain $94.38 \% \mathrm{Nb}$ and $5.62 \% \mathrm{Ti}$ by weight.

Figure 4 shows the SEM microstructure image of sample A magnified by 2500 . The EDS analysis took place in the light-coloured triangular area and needle-shaped areas in the

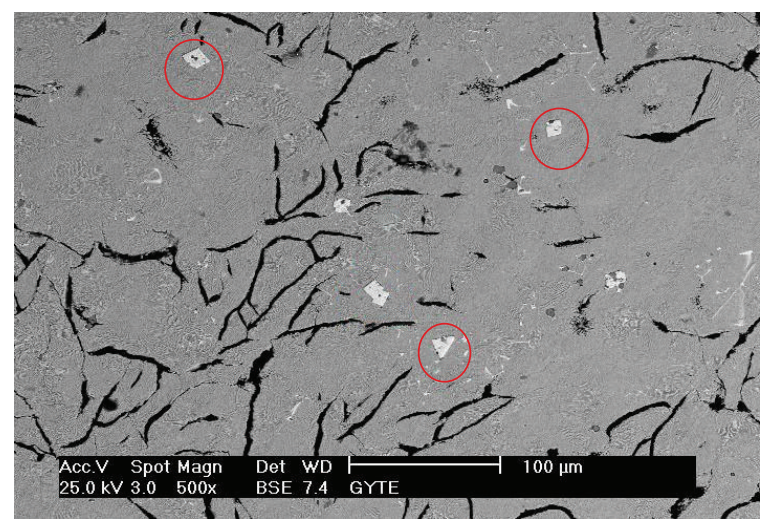

(a)

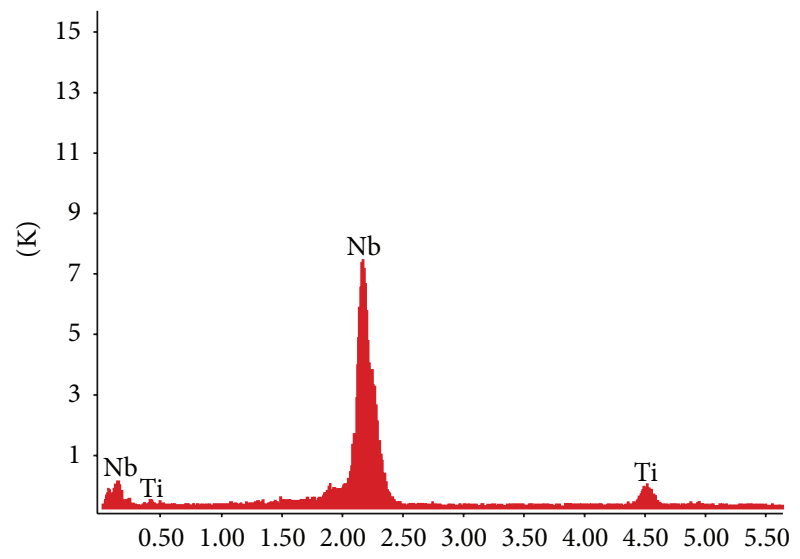

(b)

FIgURE 2: Microstructure image and EDS analysis of sample A.

picture and it is confirmed that the light-coloured areas have high $\mathrm{Nb}$ concentration. The areas with high $\mathrm{Nb}$ concentration are spread like needles in the grey cast matrix structure.

Figure 5 shows the SEM microstructure image of sample A magnified by 16000 . As can be seen in the picture, the lightcoloured $\mathrm{Nb}$ particle zone seems to have the same altitude as the pearlite $\left(\mathrm{Fe}_{3} \mathrm{C}\right)$ structure in the matrix structure. Samples are exposed to abrasion during preparation and polishing. The pearlite phase and the phase with rich $\mathrm{Nb}$ concentration 




(a)

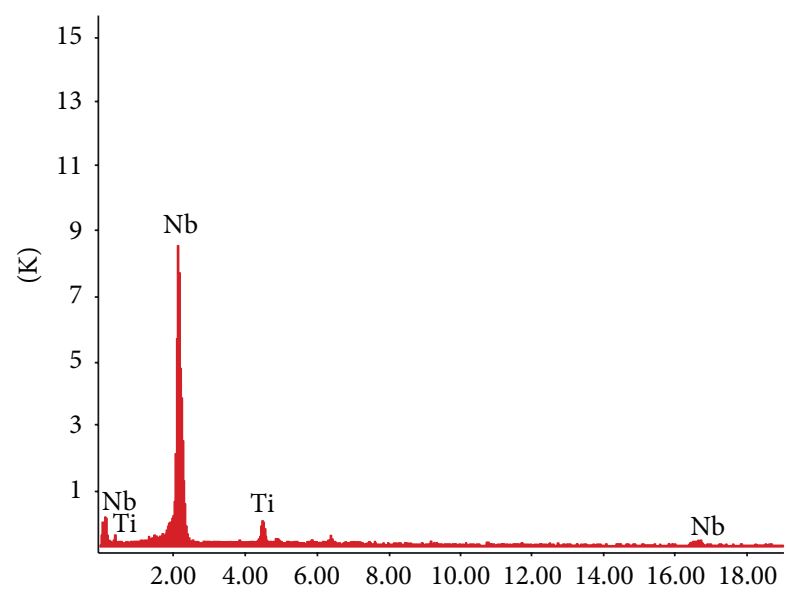

(b)

FIgURE 3: Microstructure image and EDS analysis of sample B.

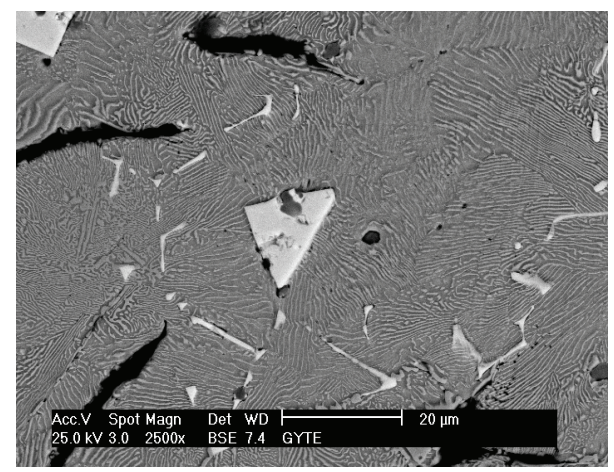

FIGURE 4: SEM microstructure image of sample A.

with a partially higher abrasion resistance can be seen to have different elevations.

3.2. XRD Results. X-ray diffraction analysis was done using a Rigaku D-max 2200 and the results are shown in Figure 6. The results of the phase analysis have proved the presence of niobium carbide and alpha iron (ferrite). A sample containing $0.641 \%$ by weight of niobium $\mathrm{NbC}$ phase was detected.

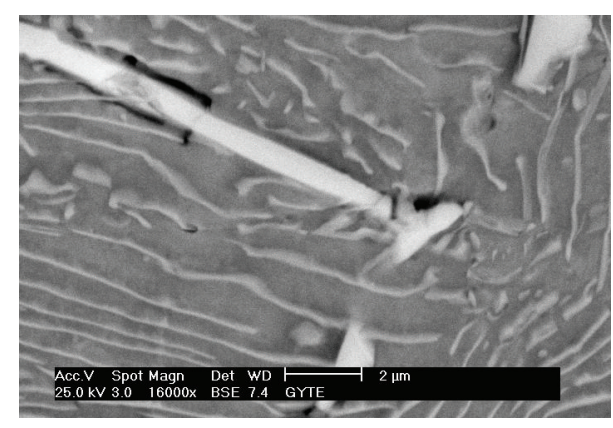

FIGURE 5: SEM microstructure image of sample A.

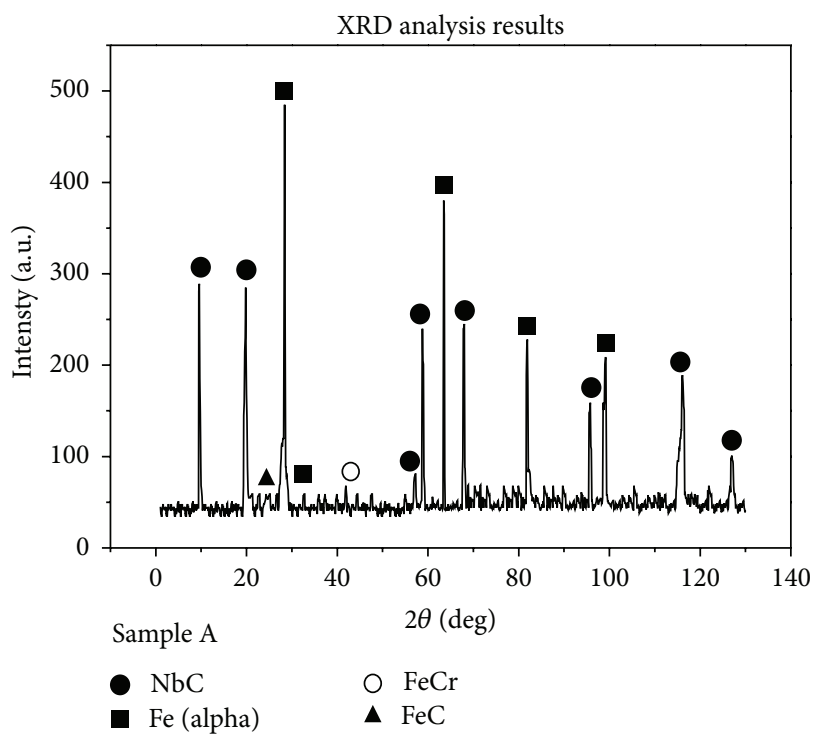

FIGURE 6: XRD analysis of sample A.

In addition, $\mathrm{FEC}$ and $\mathrm{FeCr}$ structures have been identified. The hardness values of samples were measured, and the increase in hardness with increasing amounts of niobium, and likewise the increase in tensile strength of the structure, is thought to be due to the increased amount of $\mathrm{NbC}$ phase.

3.3. Abrasion Test and Results. Abrasion testing was done using a tribometer from CSM, as shown in Figure 7. Abrasion tests were performed on six different surfaces of the samples $\mathrm{A}, \mathrm{B}, \mathrm{C}$, and D, which had been previously prepared for metallographic analysis. A load of $60 \mathrm{~N}$ was applied to the sample and the abrasion zone was adjusted to $12 \mathrm{~mm}$. The wear tip moved at $15 \mathrm{~mm} / \mathrm{s}$ and a WC tip was used as the sample abrasive. Abrasion tests were performed on six different surfaces of each sample, and the duration of each surface abrasion test was 10 minutes.

In order to measure the sample's abrasion surface, the DEKTAK 8 VEECO smoothness indicator shown in Figure 8 was used. The surface topography of the sample was analysed with the surface profilometer. Hachure areas of $5 \mathrm{~mm}$ were hatched for 60 seconds under a $5 \mathrm{mg}$ load by a diamond tip with a radius of $5 \mu \mathrm{m}$. Every sample was subjected to 10 hachures with $1000 \mu \mathrm{m}$ spaces. Figure 9 shows the amount of 


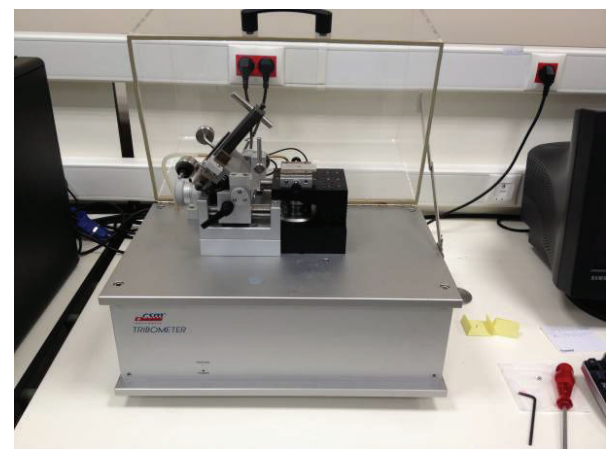

Figure 7: Abrasion test device.

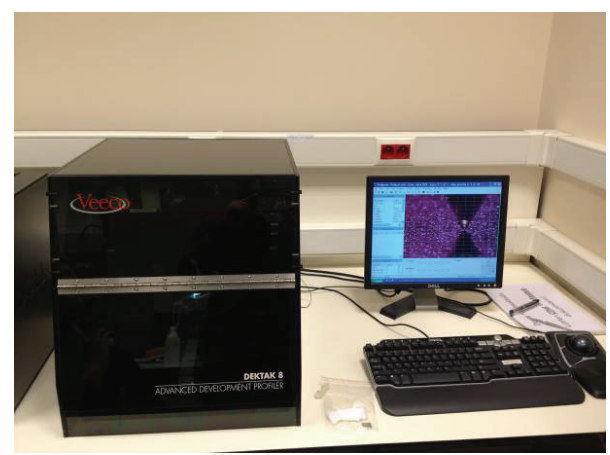

FIGURE 8: Surface profilometer.

abrasion of samples A, B, C, and D. All samples were subjected to the abrasion test six times. It was determined that sample A has the minimum amount of abrasion and the amount of abrasion decreases in inverse proportion to the increment of $\mathrm{Nb}$ in the sample.

3.4. Tensile Test and Results. According to the EN 1561 grey cast iron standards, six tensile rods were made from each of the casting samples, A, B, C, and D. The tensile rods were processed to have radii of $10 \mathrm{~mm}$ and were subjected to tensile testing by Instron tensile device with a speed of $1 \mathrm{~mm} / \mathrm{min}$. The tensile test results are shown in Figure 10. After the tensile test, it was found that B, C, and D had not changed while the tensile strength of sample A showed a slight increased. Also, the values of the tensile strength in sample A, a wider range showed. The reason for this, with the addition of niobium, which in the structure is relatively more hard than the increase of niobium carbide phase, may result in a slight increase in tensile strength.

3.5. Hardness Measurement and Results. Brinell hardness measurement of the samples were done using hardened steel ball $10 \mathrm{~mm}$ in diameter according to the EN 10003-1 Brinell hardness measurement standards. During the hardness measurement, the force applied was $3000 \mathrm{~kg}$. The hardness measurement results for the six measurements taken from each sample are shown in Figure 11. The hardness measurement showed that the highest hardness value is measured in sample A and the lowest hardness value is determined in sample D.

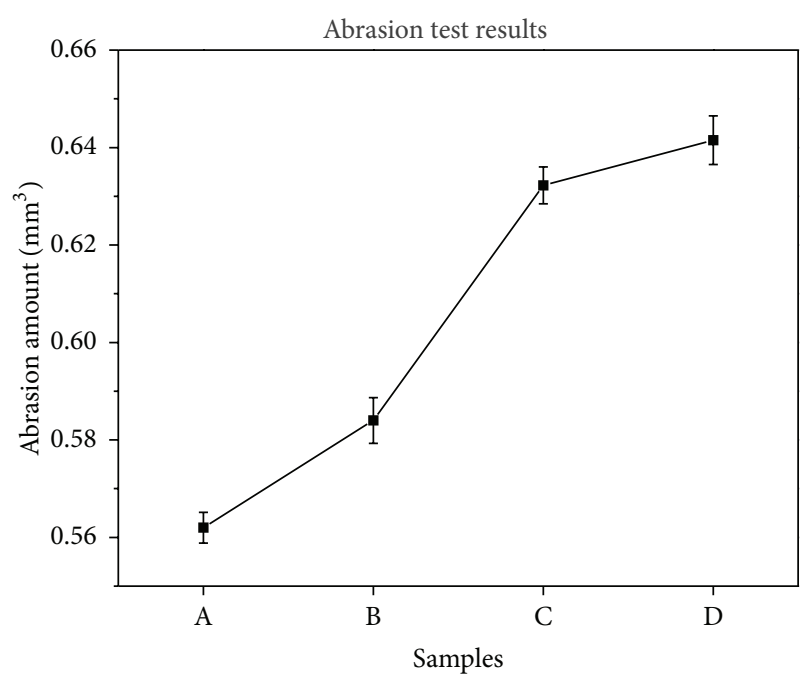
(A) $\mathrm{wt} \% 0.646 \mathrm{Nb}$
(B) $w t \% 0.431 \mathrm{Nb}$
(C) $\mathrm{wt} \% 0.151 \mathrm{Nb}$
(D) $\mathrm{wt} \% 0.019 \mathrm{Nb}$

FIGURE 9: Amount of abrasion of the samples after the abrasion test.

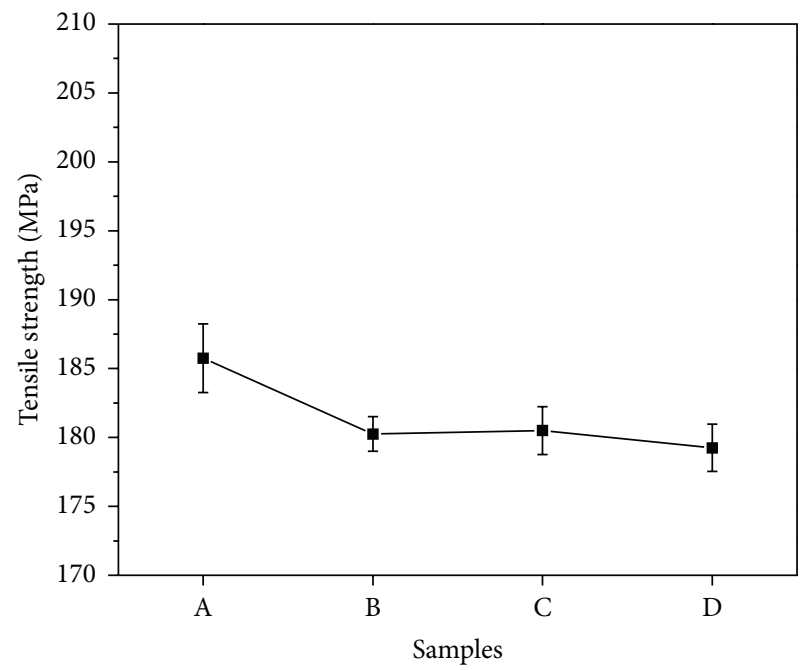
(A) $w t \% 0.646 \mathrm{Nb}$
(B) $\mathrm{wt} \% 0.431 \mathrm{Nb}$
(C) $\mathrm{wt} \% 0.151 \mathrm{Nb}$
(D) $\mathrm{wt} \% 0.019 \mathrm{Nb}$

FIgURE 10: Tensile test values of samples A, B, C, and D.

This situation is similar to the variation in the tensile strength; the hardness increased linearly with the increment of niobium. The hardening effect is thought to be related to the amount of niobium carbide phase formed.

\section{Results and Discussion}

It is determined that niobium added to the chemical composition of lamellar graphite cast iron is spread evenly over the microstructure. The high carbide production affinity of 


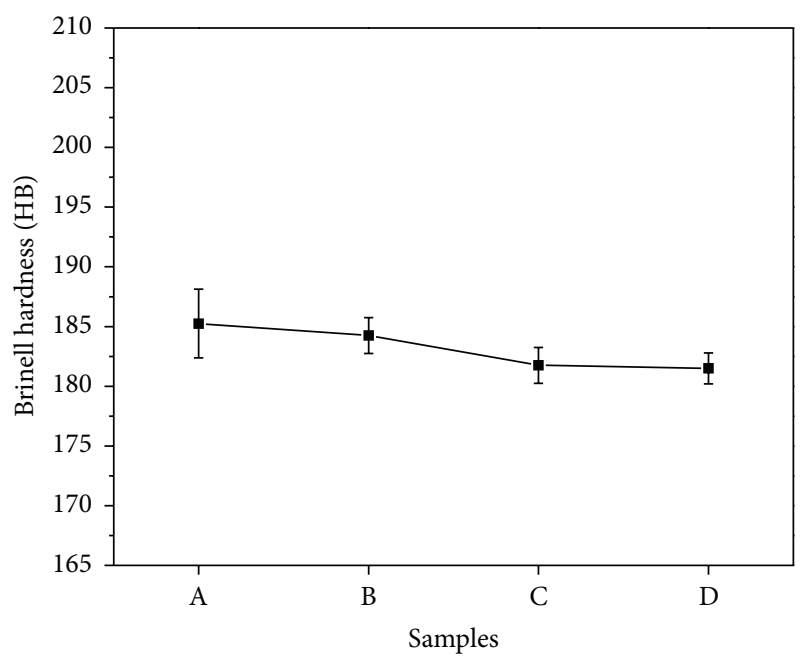
(A) $\mathrm{wt} \% 0.646 \mathrm{Nb}$
(B) $w t \% 0.431 \mathrm{Nb}$
(C) $\mathrm{wt} \% 0.151 \mathrm{Nb}$
(D) $\mathrm{wt} \% 0.019 \mathrm{Nb}$

FIGURE 11: Brinell hardness measurement values of samples A, B, C, and $\mathrm{D}$.

$\mathrm{Nb}$ causes a reaction with carbon, which produces niobium carbide. As a result, the abrasion resistance of grey cast material increases. There is a $15 \%$ difference in abrasion resistance between the sample without $\mathrm{Nb}$ in the structure and the other sample with $0.64 \% \mathrm{Nb}$ (by weight) in the structure. Niobium addition caused an increase in the abrasion resistance values. Also a linear increase in the hardness and the tensile strength of grey cast samples took place when different amounts of $\mathrm{Nb}$ were added. As seen in the results of this study, the addition of niobium in grey cast iron, improved in the values of mechanical strength and wear resistance in particular. In the manufacture of brake discs and drums in the automotive industry, the use of niobium increases the service life of vehicles, because the lower amount of wear contributes towards reducing the consumption of raw materials and energy.

\section{Conflict of Interests}

The authors declare that there is no conflict of interests regarding the publication of this paper.

\section{References}

[1] G. Balachandran, A. Vadiraj, M. Kamaraj, and E. Kazuya, "Mechanical and wear behavior of alloyed gray cast iron in the quenched and tempered and austempered conditions," Materials and Design, vol. 32, no. 7, pp. 4042-4049, 2011.

[2] M. Erdoğan and M. Karabaş, "Surface modification of lamellar graphite cast irons by using GTAW with Mosi2 and sintered B4C at different temperatures," in Proceedings of the 6th International Advanced Technologies Symposium (IATS '11), Elazığ, Turkey, May 2011.
[3] M. Şimşir, "Effect of heat treatment on fracture behavior of steel-wire-reinforced gray cast iron," International Journal of Fracture, vol. 151, no. 2, pp. 121-133, 2008.

[4] M. Moonesan, A. H. Raouf, F. Madah, and A. H. Zadeh, "Effect of alloying elements on thermal shock resistance of gray cast iron," Journal of Alloys and Compounds, vol. 520, pp. 226-231, 2012.

[5] M. Gorny and M. Kawalec, "Effects of titanium addition on microstructure and mechanical properties of thin-walled compacted graphite iron castings," Journal of Materials Engineering and Performance, vol. 22, no. 5, pp. 1519-1524, 2013.

[6] A. Vadiraj, G. Balachandran, M. Kamaraj, B. Gopalakrishna, and D. V. Rao, "Wear behavior of alloyed hypereutectic gray cast iron," Tribology International, vol. 43, no. 3, pp. 647-653, 2010.

[7] S. İziz, Cylinder Sleeve Materials, 2006.

[8] T. S. Skoblo, N. I. Sandler, V. K. Parfenyuk, and B. S. Gilman, "Influence of $\mathrm{Nb}$ additions on properties of cast iron," in Russian Casting Production, vol. 6, pp. 306-307, 1967.

[9] K. A. Valsov, Vestnik Akademii Nauk SSSR, 1, 1960.

[10] E. Pivovarsky, Hochwert Gussesien, Berlin, Germany, 1961.

[11] Chaleur et industry, 3, 1935.

[12] M. A. Tylkin, Strength and Wear Resistance of Components for Metallurgical Equipments, Metallurgizdat, Moscow, Russia, 1965. 

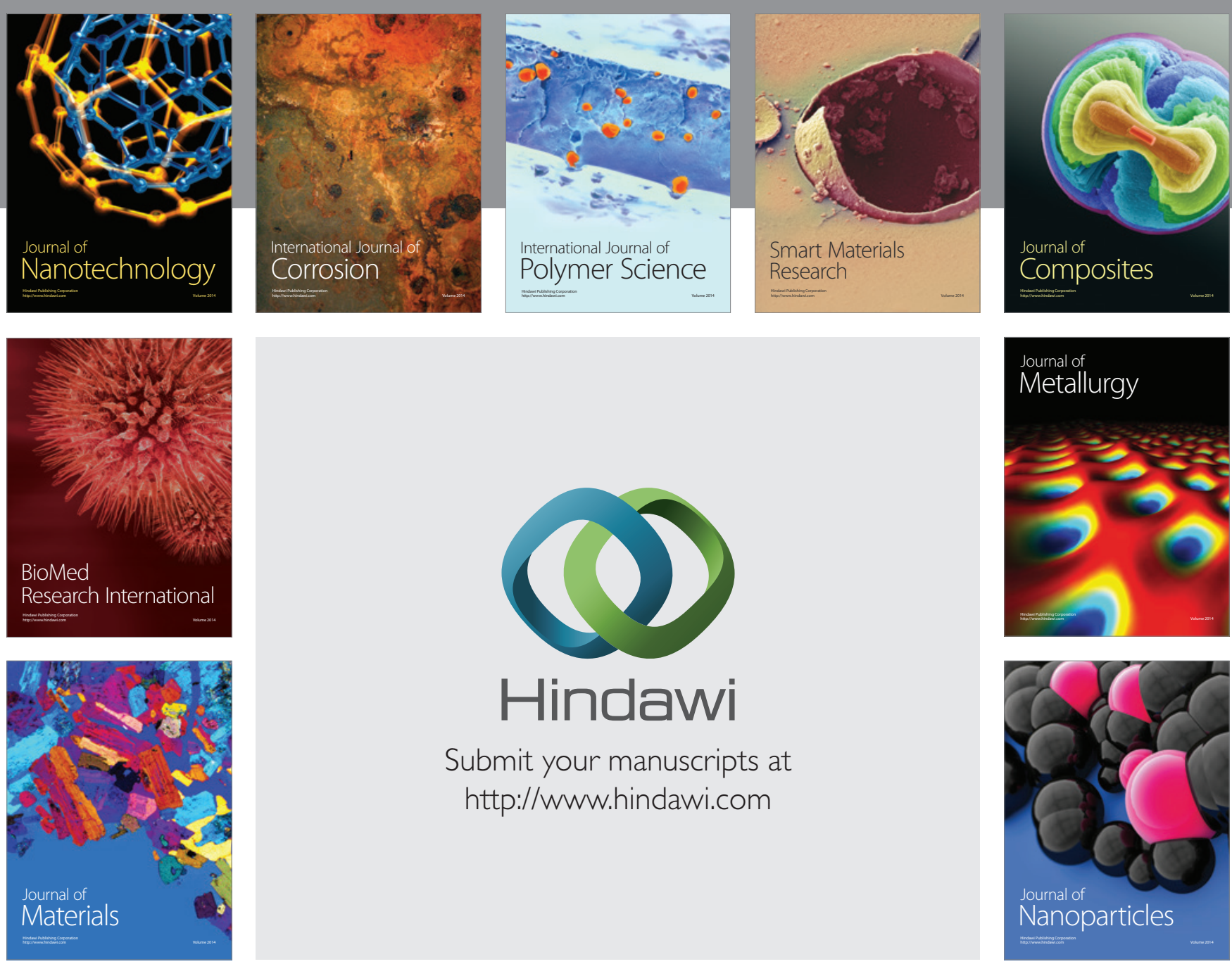

Submit your manuscripts at http://www.hindawi.com
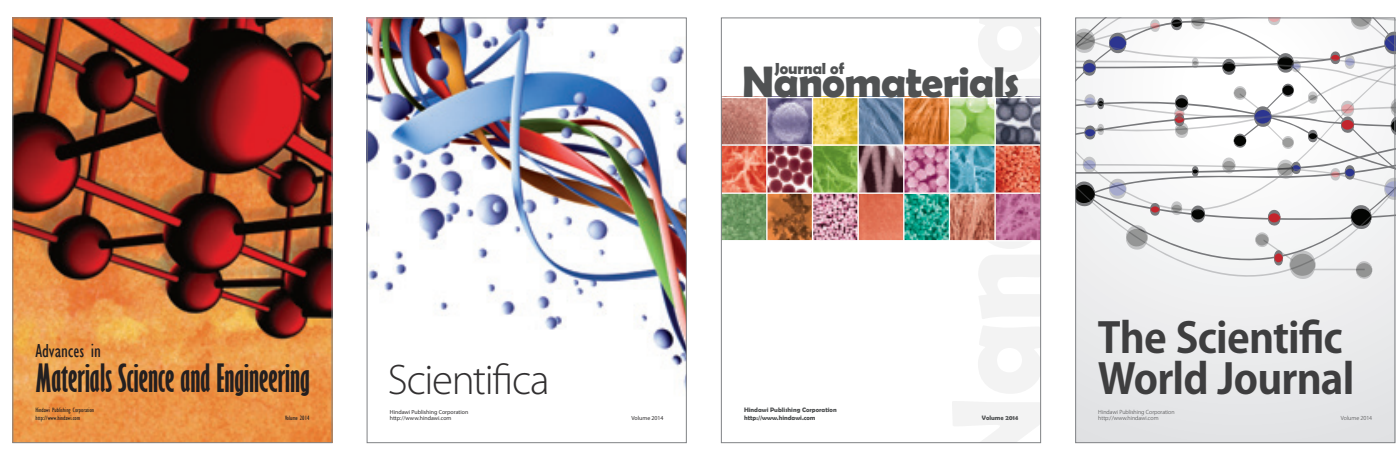

\section{The Scientific World Journal}
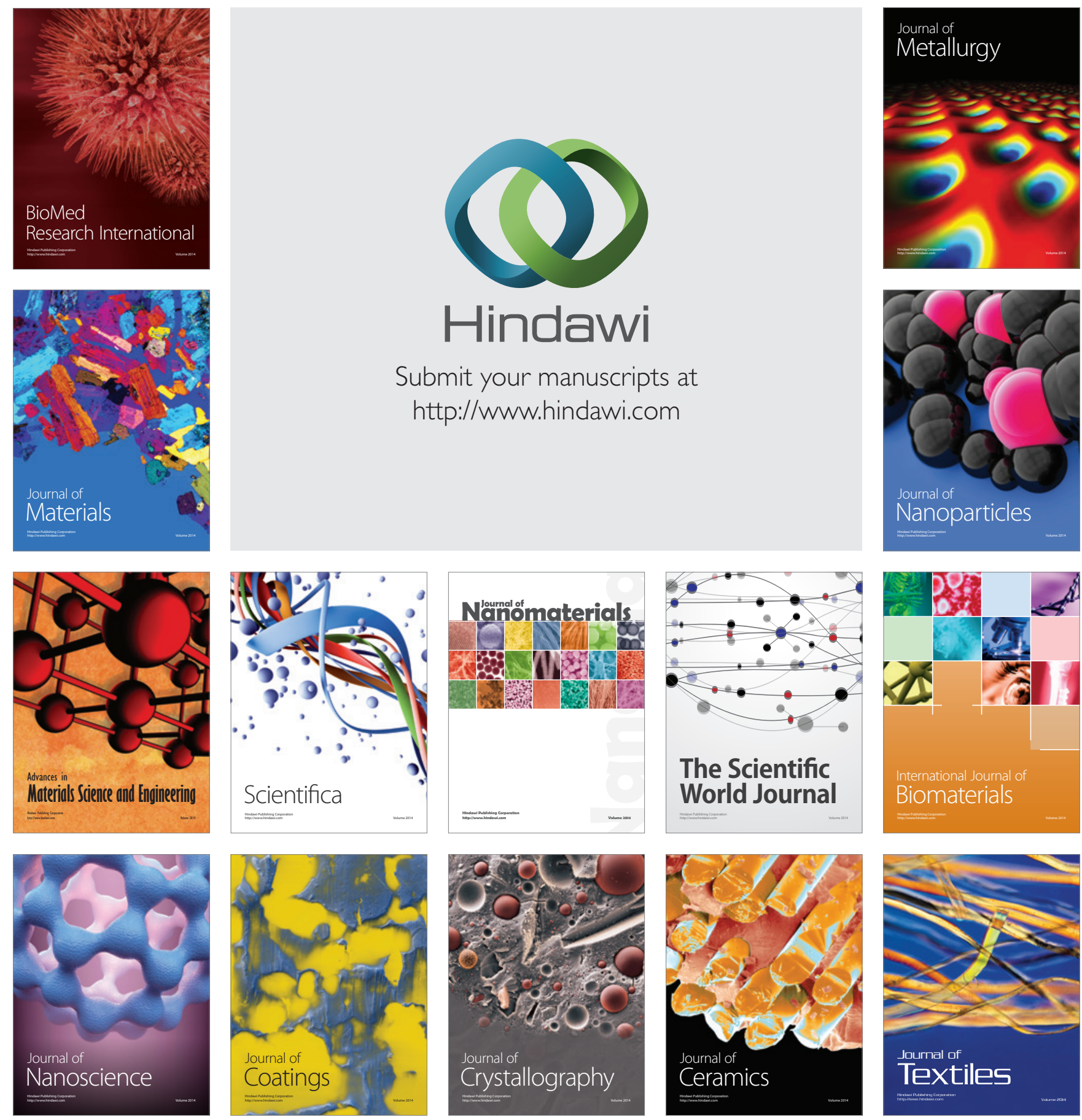